\title{
Role of serum copper and ceruloplasmin level in patients with dysfunctional uterine bleeding
}

\author{
Ketki P. Khandhadiya, Yousef Rezaei Chianeh, Pragna Rao*
}

Department of Biochemistry, Kasturba Medical College, Manipal University, Manipal - 576104, Karnataka, India

Received: 4 March 2014

Accepted: 25 March 2014

\author{
*Correspondence: \\ Dr. Pragna Rao, \\ E-mail: pragna.rao@manipal.edu,drpragnarao@gmail.com
}

(C) 2014 Khandhadiya KP et al. This is an open-access article distributed under the terms of the Creative Commons Attribution Non-Commercial License, which permits unrestricted non-commercial use, distribution, and reproduction in any medium, provided the original work is properly cited.

\begin{abstract}
Background: Objective of current study was to study serum copper and ceruloplasmin levels in abnormal endometrial angiogenesis observed in dysfunctional uterine bleeding patients.

Methods: Design: The present cross sectional study was undertaken in the departments of biochemistry and department of OBG, Kasturba medical college, Manipal University, Manipal, India. Population: This study was done in 40 females age between 18-45 years with history of, bleeding excessively for more than 3 months. (Cases: $n=20$, controls: $n=20)$. DUB was diagnosed based on history and ultrasonography. Copper was estimated using 3,5dibromo-2-pyridylazo-N-ethyl-N-3 sulphopropyl aniline. Ceruloplasmin was estimated using p-phenylene diamine (PPD) oxidase method. Endometrial thickness was obtained from USG. Hemoglobin was estimated using Drabkin's method. Main outcome measures: The level of serum copper and ceruloplasmin and hemoglobin level measured and compared with endometrial thickness in dysfunctional uterine bleeding patients. Dysfunctional uterine bleeding (DUB) is defined as abnormal endometrial bleeding in the absence of pelvic pathology.

Results: Mean levels of serum copper $(191.99 \pm 73.06) \mu \mathrm{g} / \mathrm{dl}$ and ceruloplasmin $(60.42 \pm 18.40) \mathrm{mg} / \mathrm{dl}$ were increased in DUB patients when compared to control, $70 \%$ of DUB patients and $55 \%$ of controls had copper levels higher than the biological reference range in the general population. Ceruloplasmin has negative correlation with endometrial thickness in patients with DUB. $(\mathrm{P}=0.019 \mathrm{r}=-0.5)$.

Conclusions: This study has concluded that serum copper and ceruloplasmin could be a sensitive indicator of angiogenesis in endometrium leading to DUB in females.
\end{abstract}

Keywords: Dysfunctional uterine bleeding (DUB), Angiogenesis, Copper, Ceruloplasmin, Endometrial thickness

\section{INTRODUCTION}

Dysfunctional uterine bleeding (DUB) is defined as abnormal endometrial bleeding in the absence of pelvic pathology. ${ }^{1}$ There are two types of DUB, ovulatory and anovulatory. $80 \%$ of women with ovulatory DUB usually are in their reproductive age, but anovulatory DUB is seen during perimenopause and menarche. $95 \%$ of abnormal uterine bleeding in the case of DUB category, are due to anovulation. A Blood loss of more $80 \mathrm{ml}$ per menstrual cycle is considered an excess blood loss and eventually results in an iron deficiency anemia and possibly abnormal hematocrit. The menstrual cycle is considered to be normal if the cycle is in the range of 28 \pm 7 days; the approximate blood loss is $30 \mathrm{ml}$ or may be more without exceeding more than $80 \mathrm{ml}$ per cycle. Abnormal endometrial bleeding is not restricted in any age group but it's very predominant in adolescence.

Numerous endogenous and exogenous factors identified to have direct and indirect role in overall angiogenesis in the endometrium of DUB patients. Formation of blood vessels in human endometrium are potentially similar to endometriotic lesions, that blood vessels grow and regress during every menstrual cycle and their process is controlled by hormones like; oestrogen, progesterone. ${ }^{2}$ 
However, mechanism of endometrial angiogenesis is a complex process that evidence has been shown; estrogen can act as an inhibitor and a stimulator of angiogenesis under different circumstances (Girling and Rogers, 2005). A large number of angiogenic factors and inhibitors have been identified in human endometrium beside hormones. Although the precise role they play in regulating angiogenesis during the menstrual cycle and pregnancy remains to be elucidated. Any disturbed in normal menstrual cycle would ultimately result in unchanged state of estrogen secretion and lead to DUB. Approximately $30 \%$ of all gynecologic patients have DUB. ${ }^{3}$

Copper is an essential trace element for all the living organisms ${ }^{4}$ and is one of the key requirements for angiogenesis. Hence the activity of several angiogenic factors directly or indirectly depends upon it. ${ }^{5}$ Ceruloplasmin (ferroxidase I) and ferroxidase II is a copper containing enzyme which has a capacity of oxidizing iron to a form that could be transported to the site of erythropoiesis. Although the physiological importance and complete mechanism of these reactions are not yet known. ${ }^{6,7}$

Ceruloplasmin also serves as a cofactor for many enzymatic reactions. ${ }^{8}$ Ceruloplasmin also acts as an antioxidant. ${ }^{9}$ Higher concentrations of ceruloplasmin have known to have a role in numerous cancers. ${ }^{10}$

The thickness of the endometrium in DUB is measured by ultrasound. If necessary, a layer of endometrium is surgically removed by curettage.

The aim of this study is to examine whether patients with excessive bleeding brought about by hyperplasia of the endometrium had associated elevation of serum copper and ceruloplasmin both of which are potent angiogenic initiators.

\section{METHODS}

Ethical committee clearance was obtained. A study was done in women in the age group 18-45 years, nonpregnant females, bleeding excessively for more than 3 months. (Cases: $n=20$, controls: $n=20$ ). DUB was diagnosed based on history and ultrasonography. ${ }^{11}$ Copper was estimated using 3,5- dibromo-2-pyridylazoN-ethyl-N-3 sulphopropyl aniline. Ceruloplasmin was estimated using p-phenylene diamine (PPD) oxidase method. Endometrial thickness was obtained from USG. Hemoglobin was estimated using Drabkin's method.

\section{RESULTS}

The present cross sectional study was undertaken in the departments of biochemistry and OBG and gynaecology, Kasturba medical college, Manipal University, Manipal. Institutional ethics committee gave permission to undertake this study.
This study included two groups. The first group were DUB patients aged between 15 to 45 years and the second group included age matched non-pregnant, healthy women with normal menstrual cycles.

The serum copper, serum ceruloplasmin and haemoglobin level were estimated and correlated with endometrial thickness ( $\mathrm{mm}$ ) as measured by ultrasound.

The biological reference range for serum copper is 80$155(\mu \mathrm{g} / \mathrm{dl})$ and for ceruloplasmin is $31-51(\mathrm{mg} / \mathrm{dl})$. Data was analysed by SPSS 16 and student paired ' $t$ ' test with $P$ value $<0.1$. The concentrations of serum ceruloplasmin, serum copper and endometrial thickness are shown in Table 1 with regard to biological reference range.

Table 1: percentage of patients and controls who had copper and ceruloplasmin levels within and greater than biological reference range (BRR).

\begin{tabular}{|c|c|c|c|}
\hline & BRR 80-155 & BRR & $\begin{array}{l}\mathbf{P} \\
\text { value }\end{array}$ \\
\hline \multicolumn{4}{|c|}{ Patients (group 1) } \\
\hline $\mathrm{N}(20)$ & $6(30 \%)$ & $14(70 \%)$ & \\
\hline $\begin{array}{l}\text { Serum copper } \\
(\mu \mathrm{g} / \mathrm{dl})\end{array}$ & $118.14 \pm 21.69$ & $225.88 \pm 58.92$ & $<0.010$ \\
\hline $\begin{array}{l}\text { Serum } \\
\text { ceruloplasmin } \\
(\mathrm{mg} / \mathrm{dl})\end{array}$ & $53.7 \pm 14.17 *$ & $63.27 \pm 19.7 * *$ & $<0.569$ \\
\hline $\begin{array}{l}\text { Endometrial } \\
\text { thickness } \\
(\mathrm{mm})\end{array}$ & $9.15 \pm 3.99$ & $10.33 \pm 2.7 * * *$ & $<0.5$ \\
\hline \multicolumn{4}{|c|}{ Control (group 2) } \\
\hline $\mathrm{N}(20)$ & $9(45 \%)$ & $11(55 \%)$ & \\
\hline $\begin{array}{l}\text { Serum copper } \\
(\mu \mathrm{g} / \mathrm{dl})\end{array}$ & $119.71 \pm 32.99$ & $219.89 \pm 59.25$ & $<0.005$ \\
\hline $\begin{array}{l}\text { Serum } \\
\text { ceruloplasmin }\end{array}$ & $32.48 \pm 18.53 *$ & $\begin{array}{l}31.26 \pm \\
14.99 * *\end{array}$ & $<0.1$ \\
\hline $\begin{array}{l}\text { Endometrial } \\
\text { thickness } \\
(\mathrm{mm})\end{array}$ & $9.3 \pm 3.18$ & $9.22 \pm 2.30 * * *$ & $<0.1$ \\
\hline
\end{tabular}

$\mathrm{P}<0.05^{*}$ ceruloplasmin is higher in DUB patients (group 1) when compared to control (group 2) with regard to the normal biological reference of copper.

$\mathrm{P}<0.001 * *$ ceruloplasmin is higher in DUB patients (group 1) when compared to control (group 2) with regard to a higher biological reference range of copper.

$\mathrm{P}<0.05 * * *$ Endometrial thickness shows significant increase in DUB patients (group 1) when compare to controls (group 2) with regard to a higher biological reference range of copper.

Concentration of serum copper, serum ceruloplasmin and hemoglobin in patients with DUB (group 1) and control (group 2) and endometrial thickness are shown in Table 2. 
Table 2: Concentration of serum copper, serum ceruloplasmin and hemoglobin in patients with DUB (group 1) and control (group 2). Endometrial thickness measured by ultrasound.

\begin{tabular}{|ll|l|}
\hline Variable & Group 1 $(\mathbf{n = 2 0})$ & Group 2 $(\mathbf{n = 2 0})$ \\
\hline Serum copper $(\mu \mathrm{g} / \mathrm{dl})$ & $191.99 \pm 73.06$ & $167.62 \pm 61.27$ \\
\hline $\begin{array}{l}\text { Serum ceruloplasmin } \\
(\mathrm{mg} / \mathrm{dl})\end{array}$ & $60.42 \pm 18.40$ & $31.8 \pm 16.23$ \\
\hline Hemoglobin $(\mathrm{gm} / \mathrm{dl})$ & $10.245 \pm 2.25$ & $11.32 \pm 1.23$ \\
\hline $\begin{array}{l}\text { Endometrial thickness } \\
(\mathrm{mm})\end{array}$ & $9.615 \pm 3.40$ & $9.26 \pm 2.65$ \\
\hline
\end{tabular}

Table 1 shows the mean and SD of both controls and patient in all the variables and there is a considerable difference between copper and ceruloplasmin when compare to endometrial thickness. This also indicates that even in control serum copper level is increased more than biological reference range. In this study more than $70 \%$ of patients are having a serum copper concentration more than biological reference range with increase endometrial thickness whereas $55 \%$ of controls are having elevated copper but a lesser increase in endometrial thickness. There were significant decreases in the percentage of patients having $\mathrm{Hb}$ concentration more than $11(\mathrm{gm} / \mathrm{dl})$. $45 \%$ of patients and $60 \%$ of control are having $\mathrm{Hb}$ more than $11(\mathrm{mg} / \mathrm{dl})$. This could be as a result of excessive bleeding in DUB patients. To see the role of copper and a major copper-binding molecule in blood (ceruloplasmin) on dysfunctional uterine bleeding, we have studied 20 DUB patients aged between $15-45$ years (group 1) and compared with 20 age matched nonpregnant healthy women with normal menstrual cycle (group 2).when serum copper and ceruloplasmin levels compared between patients and controls. There was a significant increase in levels of serum ceruloploasmin (P $<0.001$ ) in DUB patients with regard to a higher biological reference range of copper (Table 1). The increased serum copper concentration observed in patients $(70 \%)$ as well as control $(55 \%)$, when it is compared with serum ceruloplasmin it shows significant increase in those patients with increase serum copper level. The ultrasonographically measured endometrial thickness showed increased thickness among the patient group ( $\mathrm{P}<0.05)$. Serum copper, which is an obligatory cofactor of angiogenesis was measured in patients and controls.serum copper levels were higher (225.88 \pm $58.92)$ in DUB patients than in controls $(219.89 \pm 59.25)$. $70 \%$ of the patients showed a serum copper level higher than biological reference range, this in contrast with $55 \%$ of the controls that showed serum copper higher than biological reference range (Table 1). It shows a biologically significant of copper as an angiogenic stimulator in development of dysfunctional uterine bleeding. This study has shown that some copper and ceruloplasmin could be a sensitive indicator of angiogenesis in DUB patient (Table 1) the specificity is increased when both the parameters are measured together with a higher direct correlation. Analysis of table 1 indicates that serum ceruloplasmin as a copper binding protein in serum could exert a significant role in angiogenesis in endometrium leading to DUB. Serum copper levels alone did not correlate with endometrial thickness. In DUB patients $\mathrm{Hb}$ level were significantly decreased when compared to control. This may be due to excessive bleeding in DUB patients (Table 2).

\section{DISCUSSION}

Copper regulate the transcription of genes, so copper levels are essential regulatory or inhibitory factor for transcription of specific gene. ${ }^{11}$ Ceruloplasmin may function as an antioxidant in two different ways. Free copper and iron ions are powerful catalysts of free radical damage. By binding copper, ceruloplasmin prevents free copper ions from catalyzing oxidative damage (12). If serum copper and ceruloplasmin levels fall less than $30 \%$ of its normal biological reference range then considers to be in a state of severe copper deficiency. Anemia and unresponsive to iron therapy is a sign of copper deficiency if corrected by copper supplementation. The anemia is consider to be a result of defective iron mobilization due to decreased ceruloplasmin activity. ${ }^{6,11}$

Acute copper poisoning has occurred through the contamination of beverages by storage in coppercontaining containers as well as from contaminated water supplies. ${ }^{9}$ In the U.S., the health-based guideline for a maximum water copper concentration of $1.3 \mathrm{mg} / \mathrm{liter}$ is enforced by the Environmental Protection Agency (EPA). ${ }^{10}$ Symptoms of acute copper toxicity include abdominal pain, nausea, vomiting, and diarrhea, which help prevent additional ingestion and absorption of copper. More serious signs of acute copper toxicity include severe liver damage, kidney failure, coma, and death. The U.S. Food and Nutrition Board (FNB) set the tolerable upper level of intake (UL) for copper at 10 $\mathrm{mg}$ /day from food and supplements. ${ }^{13}$ It should be noted that individuals with genetic disorders affecting copper metabolism (e.g., Wilson's disease, Indian childhood cirrhosis, and idiopathic copper toxicosis) may be at risk for adverse effects of chronic copper toxicity at significantly lower intake levels. ${ }^{14,15}$

Copper chelation has shown to inhibit angiogenesis (Finney et al., 2007) copper containing Intra Uterine Devices (IUD) increases inflammatory action and uterine bleeding (Kulier et al., 2006). It has been hypothesized that elevated serum copper and VEGF levels could be associated with menorrhagia, which is excessive menstrual bleeding in the absence of a well-defined pelvic pathology, often referred to as Dysfunctional Uterine bleeding. ${ }^{16}$ The role of angiogenic growth factors had investigated beyond the DUB complication, for example; pre-eclampsia and placenta, pregnancy related complication and also involvement of some of the enzyme in oral cancer and correlation with angiogenesis related process and the progression of cancer. ${ }^{17-19}$

There is a relatively strong association between anovulation and DUB in adolescents. Studies on 
adolescent females for 5 years after menarche note that estrogen, progesterone, $\mathrm{LH}$, and FSH values are all below normal adult levels in year 1; estradiol levels increase to normal adult values in year 2. By year 5, FSH and LH levels have increased gradually to near normal adult values, but serum progesterone levels are still at a low percentage of ovulatory cycles $(0 \%-63 \%)$.

During puberty, maturation of the HPO axis is characterized by an increase in the frequency and amplitude of pulsatile GnRH, which initiates and regulates secretion of pituitary gonadotropins. ${ }^{20}$ During a time right before puberty, secretion of LH is frequent during the night but during the early puberty, secretion of $\mathrm{LH}$ is increasing so that the value of $\mathrm{LH}$ in circulation is essential for determining the normal ovulatory cycle. Timing of LH secretion is essential to differentiation between ovulatory cycles, as increase in basal LH and immature timing would result in anovulatory cycles. Induce follicular development that is a requirement for the ovulation has been characterized by the regular cycle and level of secretion of LH and FSH and ultimately the estrogen and progesterone are fundamental factor for physiology of endometrium. Over secretion of estrogen causes out grows of blood vessels and change in endometrial architecture and ultimately endometrial growth that lead to partial break down and shedding in an irregular manner.

Increased estrogen has a negative effect on the hypothalamus and pituitary gland, causing reductions in GnRH, FSH, LH, and estrogen. This process results in vasoconstriction and collapse of the thickened, hyperplastic endometrial lining, leading to heavy and often prolonged bleeding. Without ovulation and subsequent progesterone production, a state of unopposed estrogen occurs, causing dilatation of the spiral arterial supply in the endometrium, and resulting in endometrial proliferation and associated abnormal height without proper structural integrity. ${ }^{21}$ Large, thin-walled, tortuous, superficial endometrial vessels often can be demonstrated on the surface of the hyperplastic endometrium; increased fragility is a probable contributor to increased blood loss. Unopposed estrogen has a direct effect on the uterine blood supply by reducing vascular tone and possibly an indirect effect by inhibiting vasopressin release, leading to vasodilatation and increased blood flow. ${ }^{22,23}$ Unopposed estrogen also stimulates stromal VEGF expression, which may contribute to distributed angiogenesis. ${ }^{24,25}$ In addition, endometrium exposed to prolonged, unopposed estrogen synthesizes less prostaglandin (PG) and a higher proportion of Prostaglandin E (PGE) than PGF. ${ }^{26}$ The endometrium often breaks down unevenly, even when circulating estrogen concentrations are high or rising, with scattered red patches as seen in hysteroscopy, corresponding to thrombotic foci of necrotic disintegration, adjacent to the abnormally proliferated endometrium. ${ }^{27,28}$ An increased production of endometrial nitric oxide (endothelium derived relaxing factor) in response to excessive and unopposed estrogen has been postulated as another mechanism leading to excessive blood loss in anovulatory menstruation. ${ }^{29}$ Although anovulation is the most common finding associated with DUB, a number of ovulatory patients have intermenstrual bleeding. The mechanism of this particular disorder is unclear. In addition, conditions of prolonged progesterone excretion after ovulation, as a result of persistent corpus luteum cyst (Halban's disease), can result in 6 to 8 weeks of amenorrhea followed by irregular menstrual flow.

\section{ACKNOWLEDGMENTS}

We thank Dr. Pradeep Kumar, Dean, KMC, Manipal for providing resources and guiding us to complete this project.

\section{Funding: No funding sources}

Conflict of interest: None declared

Ethical approval: The study was approved by the institutional ethics committee

\section{REFERENCES}

1. Chianeh Yousef Rezaei, Pragna Rao. Role of copper and vascular endothelial growth factor (VEGF) on endometrial angiogenesis. J Krishna Inst Med Sci Uni. 2013; Jul-Dec;2(2):6-17.

2. Chianeh Yousef Rezaei, Pragna Rao. Molecular and hormonal regulation of angiogenesis in proliferative endometrium. Int J Res Med Sci. 2014;2(1):1-9.

3. Wren BG. Dysfunctional uterine bleeding. Aust Fam Physician. 1998;27:371-7.

4. Hiroko Kodama, Chie Fujisawa. Copper metabolism and inherited copper transport disorders: molecular mechanisms, screening, and treatment. Metallomics. 2009; 1:42-52.

5. Brem S, Wotoczek-Obadia MC. Regulation of angiogenesis by copper reduction and penicillamine: antagonism of cytokine and growth factor activity. In: Brem S, Wotoczek-Obadia MC, eds. AACR Special Conference. Orlando, Fla; Angiogenesis and Cancer Research; 1998: 24-28.

6. Turnlund JR. Copper. In: Shils ME, Shike M, Ross AC, Caballero B, Cousins RJ, eds. Modern Nutrition in Health and Disease. 10th ed. Philadelphia: Lippincott Williams \& Wilkins; 2006: 286-299.

7. Harris ED. Copper. In: O'Dell BL, Sunde RA, eds. Handbook of Nutritionally Essential Minerals. New York: Marcel Dekker, Inc; 1997: 231-273.

8. Kaunitz AM. DMPA: a new contraception option. Contemp Ob/Gyn. 1993 Jan;38:19-34.

9. Bremner I. Manifestations of copper excess. Am J Clin Nutr. 1998;67(5 Suppl):1069S-73S.

10. Fitzgerald DJ. Safety guidelines for copper in water. Am J Clin Nutr. 1998;67(5 Suppl):1098S-102S.

11. Afshan Rafi, Ramakrishna Devaki, K. Sabitha, Shruti Mohanty, Pragna Rao. Importance of serum copper and vascular endothelial growth factor 
(VEGF-A) levels in postmenopausal bleeding. Indian J Clin Biochem. 2013 Apr;28(2):147-51.

12. Johnson MA, Fischer JG, Kays SE. Is copper an antioxidant nutrient? Crit Rev Food Sci Nutr. 1992;32(1):1-31.

13. Food and Nutrition Board, Institute of Medicine. Copper. In: Food and Nutrition Board, eds. Dietary reference intakes for vitamin $\mathrm{A}$, vitamin $\mathrm{K}$, boron, chromium, copper, iodine, iron, manganese, molybdenum, nickel, silicon, vanadium, and zinc. Washington, D.C.: National Academy Press; 2001: 224-257.

14. Turnlund JR, Jacob RA, Keen CL et al. Long-term high copper intake: effects on indexes of copper status, antioxidant status, and immune function in young men. Am J Clin Nutr. 2004;79(6):1037-44.

15. Turnlund JR, Keyes WR, Kim SK, Domek JM. Long-term high copper intake: effects on copper absorption, retention, and homeostasis in men. Am J Clin Nutr. 2005;81(4):822-8.

16. Afshan Rafi, D. Ramkrishna, K. Sabitha, S. Mohaty, Pragna Rao. Serum copper and vascular endothelial growth factor (VEGF) in dysfunctional uterine bleeding. Am J Biochem Molecul Biol. 2011;1(3):284-90.

17. Bagheri, Azadeh, Yousef Rezaei Chianeh, Pragna Rao. Role of angiogenic factors in recurrent pregnancy loss. Int J Reprod Contracept Obstet Gynecol. 2013;2(4):497-502.

18. Chianeh Yousef Rezaei et al. Significance of salivary phosphodiesterase level in oral squamous cell carcinoma patients. Int $\mathrm{J}$ Res Med Sci. 2013;1(4):417-20.

19. Chianeh Yousef Rezaei, Krishnananda Prabhu. Biochemical markers in saliva of patients with oral squamous cell carcinoma. Asian Pacific J Tropic Dis. 2014;4:S33-40.

20. Baughan DM. Changes in the management of patients with dysfunctional uterine bleeding. Fam Pract Recertificat. 1993;15:68-78.
21. Sanfilippo JS, Yussman MA. Gynecologic problems of adolescence. In: Lavery J, Sanfilippo JS, eds. Pediatric and Adolescent Gynecology. 2nd ed. New York: Springer-Verlag; 1985. p. 61-83.

22. Fraser IS, Hickey M, Song JY. A comparison of mechanisms underlying disturbances of bleeding caused by spontaneous dysfunctional uterine bleeding or hormonal contraception. Hum Reprod. 1996;11(2):165-78.

23. Akerlund M, Bengtsson LP, Carter AM. A technique for monitoring endometrial or decidual blood flow with an intrauterine thermisor probe. Acta Obstet Gynecol Scand. 1976;54:469-77.

24. Smith SK. Angiogenesis, vascular endothelial growth factor and the endometrium. Hum Reprod Update. 1998;4:509-19.

25. Zhang L, Rees MC, Bicknell R. The isolation and long-term culture of normal human endometrial epithelium and stroma. Expression of mRNAs for angiogenic polypeptide basally and on oestrogen and progesterone challenges. J Cell Sci. 1995;108:32331 .

26. Smith SK, Abel MH, Kelly RW et al. The synthesis of prostaglandins from persistent proliferative endometrium. J Clin Endocrinol Metab. 1982;55:284-9.

27. Brown JB, Kellar RJ, Matthew GD. Urinary oestrogen excretion in certain gynecological disorders. J Obstet Gynaecol Br Emp. 1959;66:177211.

28. Schroder R. Endometrial hyperplasia in relation to genital function. Am J Obstet Gynecol. 1954;68:294309.

29. Chwalisz K, Garfield RE. Role of nitric oxide in implantation and menstruation. Hum Reprod. 2000;15(3):96-111.

DOI: $10.5455 / 2320-1770$. ijrcog20140608

Cite this article as: Khandhadiya KP, Chianeh YR, Rao P. Role of serum copper and ceruloplasmin level in patients with dysfunctional uterine bleeding. Int J Reprod Contracept Obstet Gynecol 2014;3:330-4. 